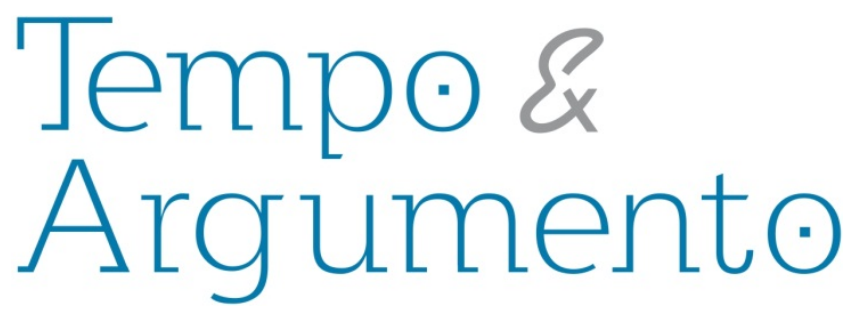

\title{
A poética do espaço: a escrita e a produção da paisagem dos verdes carnaubais assuenses (1950 - 1970)
}

\begin{abstract}
Resumo
Discute-se neste artigo a produção da paisagem dos verdes carnaubais assuenses mediante a escrita de escritores e poetas locais. Problematizam-se aqui os jogos de interesse e as possibilidades identitárias contidas na elaboração dessa paisagem da cidade do Assú, localizada no sertão do Rio Grande do Norte. Trata-se, portanto, de um estudo que pretende contribuir para o conhecimento das relações entre escrita, espaço e paisagem no âmbito do saber histórico. Parte-se do referencial teórico da análise do discurso de Foucault, que projeta a linguagem como pragmática, promotora de ações, responsável, inclusive, pela construção de objetos de saber e poder, aplicada aqui a paisagens. O método seguido é o arqueológico também de Foucault, pela oportunidade que oferece de tratar as escritas neste trabalho analisadas como enunciados e, por conseguinte, como acontecimentos discursivos. A conclusão preliminar é que os carnaubais serviram a escritores e poetas como ponto de apego para inventarem uma identidade assuense, uma identidade fabricada para (de)marcar um espaço, o "Assú dos verdes carnaubais", uma construção interessada, pois os feitores desse espaço/paisagem objetivaram fornecer funcionalidade simbólica aos carnaubais, já que a matriz econômica deles advinda parecia se esvair. Além do mais, seu alçamento à condição de símbolo local traduz a iniciativa de apropriação de um "bem vegetal" em proveito de uma cidade.
\end{abstract}

Palavras-chave: Escrita. Espaço. Assú.

\author{
Roberg Januário dos Santos \\ Mestre em História pela \\ Universidade Federal \\ de Campina Grande.
}

roberg.assu@hotmail.com

\section{Lucilvana Ferreira Barros \\ Mestre em História pela \\ Universidade Federal \\ de Campina Grande.}

lucilvanabarros@hotmail.com

\section{Para citar este artigo: \\ SANTOS, Roberg Januário dos; BARROS, Lucilvana Ferreira. A poética do espaço: a escrita e a produção da paisagem dos verdes carnaubais assuenses (1950 - 1970). Revista Tempo e Argumento, Florianópolis, v. 5, n.9, jan./jun. 2013. p. 102 - 133.}




\title{
Poetic of the space: the writing and production of the landscape of green carnaubais assuenses (1950 - 1970)
}

\begin{abstract}
This article talks about the production of the landscape of green carnaubais assuenses by means of writings of the local writers and poets. It speculates here the gamble of interest and the identity possibilities contained in elaboration of this landscape about Assu city, located in backwoods form Rio Grande do Norte. Therefore, it consists of a study that intends to contribute to the knowledge of the relations between writing, space and landscape in the place to the historical lore. Through basis theoretical of the analysis of speech from Foucault (2012), that it has the language like pragmatics and promotes actions, include being responsible for the constructions of objects of the lore and power as example of landscapes. Methodologically we operate through archaeological Foucault's method, opportunity that discourses the writing analyzed in this article and for consequent as discursive happenings. Preliminarily, we can conclude that the carnaubais served as point of addiction to writers and poets invented an assuense identity, an identity made to mark or demarcate a space: "green carnaubais assuenses", a construction interested because the foremen of this space/landscape aimed to supply symbolic functionality to carnaubais, already that the economic mold arising themselves appeared to evaporate. In addition, the raise of the carnaubais to conditions of local symbol translates the initiative of appropriation of a "well-vegetable" in benefit from a city.
\end{abstract}

Keywords: Writing. Space. Assú. 


\section{Introdução}

"[...] Todas as nossas paisagens, do parque urbano às trilhas na montanha, têm a marca de nossas persistentes $e$ inelutáveis obsessões".

Simon Schama (1996, p. 29)

Schama (1996) demonstra o quanto a paisagem contém de dimensões culturais, uma vez que a natureza só se torna paisagem quando escrita, dita e visibilizada. $\mathrm{O}$ discurso opera no sentido de traduzir seus elementos, mas essa tradução envolve percepções, sentimentos, interesses de olhar, além de desejos e devaneios espaciais. Para o autor, a paisagem deve ser compreendida como texto, devendo, portanto, ser encarada como escrita de uma sociedade, o que nos impulsiona a considerar que se é escrita também é dada a ler por seus agentes. Ele apela para as construções das paisagens mediante a utilização da natureza, tentando evidenciar os vínculos entre ela natureza e a cultura. Sua intenção é inserir, no debate sobre espaços, a historicidade das associações entre elementos da natureza e práticas humanas, entendendo a paisagem como cultura.

Desse modo, a natureza valorizada culturalmente é transformada em paisagem, decorrendo daí a formação de um conjunto de referências sobre ela, de modo a alçá-la à condição de recorte, de território, de espaço ordenado, caracterizado de acordo com os interesses e agenciamentos diversos.

Estes ambientes podem receber atribuições religiosas, históricas, artísticas ou poéticas, como ocorre com os carnaubais ${ }^{1}$ do Assú, município localizado no Vale do Açu. ${ }^{2}$

\footnotetext{
${ }^{1}$ Mata típica do Assú e região, originada da carnaúba, cuja nomenclatura científica se refere- a Copernicia cerífera. A carnaúba é uma planta típica do sertão, pertence à família das palmeiras e cresce em maior número em áreas baixas ou várzeas de rios. Vários estados do Brasil registram a presença dessa espécie, a exemplo de Pernambuco, Piauí, Paraíba, Maranhão, Minas, Tocantins, entre outros. No Rio Grande do Norte, em especial encontra-se a carnaúba nos municípios de Macaíba, Ceará-Mirim, Mossoró e Augusto Severo, destacando-se o carnaubal do Assú, que se estende até a cidade salineira de Macau. Na cidade do Assú e região do Vale, a utilização econômica da carnaúba, mediante a extração de sua cera, aconteceu com maior intensidade a partir de 1845. A cera era importada para produção de velas, discos
} 
Por isso, retornamos a Schama para perceber quão forte é a possibilidade de transformação da natureza em paisagem e como esta última se traduz em produção carregada de sentidos e interesses, pois ele mostra, por exemplo, que "a tradição poética de La douce France - "doce França” - retrata tanto uma geografia quanto uma história, a doçura de um lugar classicamente bem ordenado, onde rios, campos cultivados, pomares, vinhedos e florestas convivem em harmonioso equilíbrio" (SCHAMA, 1996, p. 26).

Por tal compreensão, acredita-se poder considerar os enunciados dos escritores aqui interrogados consultados a respeito da natureza enquanto paisagem, pois propõem uma forma de ver a natureza da cidade de tal maneira que esta emerge atrelada a elementos constitutivos do espaço, no caso, do Assú. Aqui, a natureza não é mais enfatizada por uma densa descrição utilitária e valorativa do ponto de vista econômico, como relatavam os viajantes da modernidade. A natureza será apresentada por poetas e escritores enquanto elemento simbólico, signo constitutivo da paisagem assuense. Seus elementos integrarão o cenário espacial a ponto de se tornar inspirações para poetas e músicos.

Deste modo, o presente trabalho faz parte de uma pesquisa mais ampla que investiga a construção do espaço assuense enquanto terra de história, poesia e tradição. ${ }^{3}$

Objetiva-se problematizar a produção da paisagem dos verdes carnaubais por meio de escritores e poetas locais, oportunidade que - através da ideia de descortinamento da produção dos espaços, operando mediante a análise dos discursos poéticos que se reportam ao Assú e seus carnaubais - busca-se entender como foram colocadas em

fonográficos e outros produtos, promovendo transações comerciais entre o Brasil e o mercado inglês e americano. Além do mais, por muito tempo a carnaubeira foi bastante utilizada na cidade e região para a fabricação de vários produtos e como elemento de degustação: madeira, para coberturas de construções; da palha se produziam chapéus, esteiras, bolsas, vassouras, peneiras, entre outros; do fruto da carnaúba, o sertanejo se alimentava e alimentava animais, como o gado.

${ }^{2}$ A cidade do Assú está localizada na microrregião do Vale do Açu; esta, por sua vez, situa-se na área sertaneja do estado do Rio Grande do Norte.

${ }^{3}$ Este artigo é procedente da dissertação de mestrado intitulada Cartografias identitárias do Assú: a construção de uma terra de história, poesia e tradição, defendida em março de 2013, no Programa de PósGraduação em História, da Universidade Federal de Campina Grande. 
pantera", ou seja, partimos das contribuições de Michel Foucault (2012), entendendo que os excertos aqui analisados são tidos como enunciados que possuem status de acontecimento. As escritas analisadas serão assim consideradas como partes de um discurso que constrói a paisagem assuense; por isso, não se compreendem as escritas sobre os carnaubais como naturais, mas como estratégias de produção de espaço.

\section{A emergência da terra dos carnaubais}

Em 1949, o assuense Antônio Soares de Araújo, bacharel em direito pela Faculdade de Direito de Recife e membro da Academia Norte-Rio-Grandense de Letras e do Instituto Histórico e Geográfico do Rio Grande do Norte - IHGRN -, publicava a primeira edição do livro Lira de Poti. Nesta obra, expressava seu amor a Deus, à família, à esposa Maria Amélia e à natureza, ocasião em que contemplava a paisagem do seu estado a partir de dois espaços: o litoral, correspondendo ao ambiente de Natal (com suas jangadas e praias) e a Fortaleza do Reis Magos. Por outro lado, visibilizava o sertão de solo árido, do vaqueiro, do inverno e da vegetação. O sertão, neste caso, conforme Medeiros (2013), diz respeito a Assú, cidade natal do poeta. Na referida obra, encontra-se o poema denominado Assú; nele, a paisagem é tracejada pelo poeta e nela se encontra já uma alusão aos "verdes carnaubais":

ASSÚ

(Paróquia de São João Batista)

Ao Palmério Filho

Do Cabugí além, na sertaneja plaga

Que a estiagem flagela e a chuva enche de vida,

Onde, à tarde, o nordeste acaricia, afaga,

Do verde carnaubal a copa ao alto erguida [grifos nossos]

Está, florente e bela, a cidade querida

Que é meu berço natal. Por mais singela e vaga, 


\begin{abstract}
A memória conserva, em saudade envolvida,
A impressão infantil, que o tempo não apaga.

Recordo a várzea, o rio... aspectos que vi,

A lagoa Piató, na enchente e na vazante,

O parque e o laranjal da casa em que nasci.

Recordo a voz do sino em vibração feliz

E o cordeirinho branco, esguio e vigilante, Solitário, a girar, na tôrre da matriz.
\end{abstract}

(SOARES, 1971, p. 87)

Neste poema, Antônio Soares se remete à sua cidade natal de maneira nostálgica, utilizando de sua natureza e religião para escrever sobre ela. Assim, a paisagem é montada com a várzea, o rio, a lagoa, a vegetação, o clima, entre outros, bem como com os aspectos religiosos, ocasião em que cita "o cordeirinho" no alto da matriz católica do Assú. Além disso, ainda neste poema, irá cobrir sua cidade de "verdes carnaubais" por altos, o que denota outro elemento que passou a constar em suas referências, notadamente sua perspectiva altaneira. Neste poema, os carnaubais são mostrados como componentes de uma paisagem de uma cidade bela e acolhedora, que emergirá em vários enunciados por meio de uma estética do belo e de uma tonalidade carinhosa e encantadora.

Já a professora e poetisa assuense Sinhazinha Wanderley, espacializou, em versos, sua cidade de antigamente como território harmônico, bom para se viver, lugar de tranquilidade garantido pelas características tradicionais do sertão, oportunidade em que mostrou explicitamente a saudade. A paisagem que Sinhazinha montou é de outros tempos, por ela romantizada, ancorando a visibilidade sobre o espaço assuense numa recordação pretérita, nostalgicamente reativada para fazer acontecer sensações de outros tempos e espaços. Por isso, versou sobre a noite de antigamente, oportunidade em que enunciou:

\footnotetext{
É noite, o lampadário rebrilhante

Ponteia de ouro a "urbs" sertaneja,

O pranto da saudade lagrimeja

No coração de alguém qu'está distante
} 


\begin{abstract}
A lua branca, noiva, casta amante, No rendilhado azul, perlustra, arpeja, Uma canção de amor e trinoleja, Em surdina, uma nênia soluçante.

Na várzea o vento leste açoita forte, Sussurra o palmeiral de altivo porte, Muge o gado tristonho nos currais...

Eu recordo o passado tão ditoso, Esse tempo tão breve, tão saudoso, Que se foi e não voltará jamais...
\end{abstract}

(SILVEIRA, 1990, p. 13).

Sinhazinha demonstra o momento em que afloravam suas lembranças do velho Assú, momento propício, pois a noite se apresenta escura, momento em que se apagam os elementos de outrora; os lampadários da "urbs", por mais que "faísquem", parecem não iluminar mais os tempos e espaços de então. Ao sentir o vento do leste proveniente da várzea, o sussurro dos carnaubais parece aliar-se ao mugir do gado tristonho numa entonação de nostalgia a tempos que a poetisa tanto amava, mas que não voltariam mais. A paisagem que ela desenha converge para uma face tradicional, na qual e que nesta se encontram elementos naturais intrinsecamente ligados a Assú. Assim, Sinhazinha Wanderley se expressava:

Sobranceira, erecta, majestosa, Vestindo a várzea toda de esmeralda, A carnaúba, qual vivente fada, Farfalha ao vento a coma auspiciosa.

Tudo ela dá, raiz prodigiosa Tronco lenhoso, palma flabelada, Onde a cera se encontra agasalhada, Aguardando uma sorte venturosa.

Princesa do sertão, és sentinela Qu'as flores do porvir cuidosa vela, Quão dadivosa, quão gentil és tu! 
Brota, cresce, dá flor e frutifica,

E às novas gerações cientifica

A grandeza sem par do velho Assu.

(SILVEIRA, 1990, p. 17)

A carnaubeira, para a escritora, ergue-se como princesa do sertão, sendo um símbolo imediato das terras assuenses. A grandeza da cidade estaria, assim, diretamente ligada à presença dessa espécie em suas várzeas, pois “tudo ela dá”, inclusive sensibiliza a cartografia existencial de muitos de seus escritores.

A pretensa tradição local, neste caso, não se estaria situada somente nas manifestações culturais de caráter humano, mas na própria adjetivação do Assú, terra dos verdes carnaubais. Os carnaubais se tornaram elementos pelos quais a cidade seria identificada. Já na segunda metade do século XX, particularmente entre as décadas de 1950 e 1980, se percebem estratégias enunciativas que visavam a dizer que o Assú era o território do Rio Grande do Norte, que seria reconhecido, entre outros elementos ditos “importantes”, por seus carnaubais.

Estas estratégias não escapam à materialidade e aos lugares institucionais pelos quais os enunciados emergem, até porque os autores dos discursos precisaram de sustentáculos para estes últimos, de modo que os discursos estão atrelados a lugares institucionais, capazes de respaldar tais intenções enunciativas. Nesses termos, "a terra dos carnaubais" emerge de exterioridades discursivas que, em grande parte, advêm de lugares-referência. Falamos, assim, de escritores vinculados a espaços como a Academia Norte-Rio-Grandense de Letras, criada em 1936, e ao Instituto Histórico e Geográfico do Rio Grande do Norte - IHGRN -, entre outros. Assim, deve-se considerar, em parte dos discursos sobre os carnaubais, o caso das corografias, uma vez que as matas, a hidrografia, o relevo, as fronteiras, as descrições físicas, entre outros, entravam na pauta de descrição dos membros dos institutos históricos. As descrições das riquezas vegetais faziam parte dos saberes geográficos elencados para conhecimento dos territórios. 
Além disso, ao analisar o corpus documental deste trabalho, percebemos que, no conjunto das práticas discursivas que constituem a formação discursiva ${ }^{4}$ do Assú, terra de história, poesia e tradição, uma das práticas se encarregou de produzir o espaço por meio da tradição da terra dos carnaubais. São regras anônimas, que definiram as condições de exercício da função enunciativa sobre uma espécie vegetal que faz dela símbolo do Assú. Assim, o livro do assuense Rômulo Chaves Wanderley - Canção da Terra dos Carnaubais (1965) - é emblemático para se pensar essa comunicação em situação de uso dos carnaubais. Para Rômulo, Assú seria terminante e "naturalmente" a terra dos carnaubais.

Dizer que a "terra" expressa, neste sentido, uma vontade de (de)marcação identitária, pois, assim como terra de poetas, terra dos carnaubais denota uma vontade de verdade, a demonstração de uma apropriação com vistas a inventar um atributo de pertencimento e reconhecimento de um território num dos aspectos que mais o caracterizam. É a tentativa de fixar uma imagem para que, por meio dela, se remeta ao Assú. Daí a importância de compreender com Schama (1996) que as paisagens são construídas mediante um rico depósito de mitos, lembranças e obsessões.

Descendente da família Wanderley, Rômulo pertenceu à Academia Norte-RioGrandense de Letras e ao Instituto Histórico e Geográfico do Rio Grande do Norte. Autor de uma vasta produção literária e histórica, a exemplo dos livros Panorama da Poesia Norte-Rio-Grandense (1965), Noções de História e Geografia do Rio Grande do Norte (1968) e História do Batalhão de Polícia, foi um tipo de porta-voz da cidade onde nasceu, e demonstrando forte interesse em dizer e escrever sobre ela, mesmo residindo em outro espaço. Todavia, nos detemos, neste ponto, a comentar a obra Canção da Terra dos Carnaubais (1965) naquilo que ela proporciona para discutir a construção imagética discursiva assuense, com imagens e sensibilidade auferidas da carnaubeira. Três momentos da parte poética da obra de Rômulo enunciam o Assú dos verdes carnaubais. Analisemos o primeiro:

\footnotetext{
4 De acordo com Foucault (2012), prática discursiva diz respeito às regras anônimas, históricas e determinadas no tempo e espaço que definem o exercício da função enunciativa; por outro lado, formação discursiva, na concepção deste filósofo, refere-se à certa ordem, correlações, posições e funcionamento dos enunciados, promovendo, assim, uma regularidade discursiva.
} 


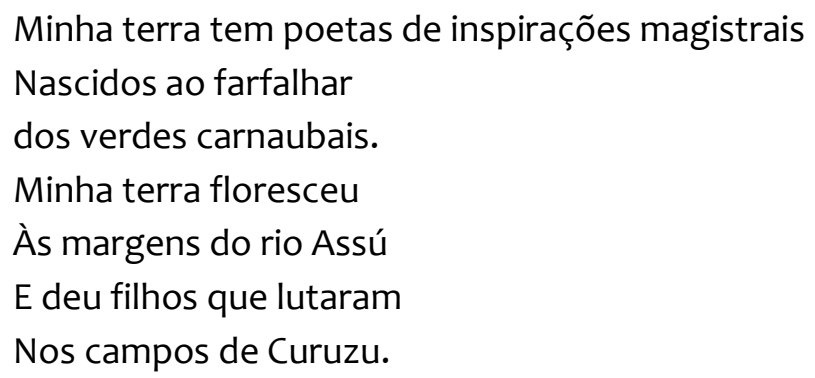

(WANDERLEY, 1965, I)

Percebemos, nestes versos, uma possível inspiração da Canção do Exílio de Gonçalves Dias, oportunidade que demonstrava apego a "minha terra"; por outro lado, as carnaubeiras são árvores pertencentes à família das palmeiras, tão decantadas pelo também maranhense poeta citado, autor da conhecida Canção do Exílio. Em Canção da Terra dos Carnaubais, canta-se uma terra de poetas com espontaneidades exemplares para poetizar, nascidos em meio à ostentação dos carnaubais, situados numa terra que floresceu às margens do Rio Assú, terra de heróis que lutaram na Guerra do Paraguai (campo do Curuzu).

Como se pode ver, em um único poema, o autor manipula enunciados para produzir uma visão sobre sua cidade natal, estrategicamente ligada ao arquivo imagéticodiscursivo inventor do espaço assuense.

Os carnaubais, nesta ótica, que influem na atmosfera poética assuense, seriam elementos fundamentais para uma imagética do espaço, pois, na segunda parte do livro, denominada "Anotações", aparecem narrativas acerca do que o autor versou anteriormente. Assim, sobre o primeiro, afirma-se que "a cidade do Assú sempre foi a cidade dos poetas. A poesia é um dom natural dos assuenses (WANDERLEY, 1965, p. 29)". Logo após, evidencia:

Estudando-se a literatura potiguar, conclui-se que nenhuma outra cidade, com exceção de Natal, tem sido berço de tantos poetas, seresteiros e boêmios. Êles nascem com vocação irresistível dos menestréis. Versejam com a inteligência que Deus Ihes dá, às vezes sem instrução e sem cultura (WANDERLEY, 1965, p. 29). 
Compreende-se, nessas palavras entusiasmadas, a postulação de um dom natural de seus habitantes para com o veio poético. Ser poeta em Assú seria uma questão de berço, vocação e destino, em que a ausência de uma cultura (dita erudita) e da instrução escolar seria suprida pela inteligência dada por Deus. Observa-se aqui um discurso com predisposições natas

Construir o espaço assuense, nestes termos de naturalidade, converge para a ideia de origem, de tradição, de presença, de um tipo de espectro ou feixe de irradiação poética capaz de pairar sobre a cidade e "influenciar todos" que ali nascem. Esta perspectiva de espaço pode ser compreendida pelo que escreveu Bachelard (1978) a respeito do espaço, de que é e por ele que alcançamos os belos fósseis de uma duração concretizada. É nele e por ele que tentamos nos situar, (de)marcar, localizar e fixar. Já a ênfase na tradição pode ser entendida pelos apontamentos de Foucault (2012), quando evidencia que esta noção permite o repensar da dispersão da história, na medida em que reduz as diferenças e isola as novidades sobre um fundo de permanência. No caso do Assú, constata-se o agenciamento de um tipo de permanência da vocação poética e de uma paisagem ímpar.

Ainda argumentando sobre seus versos, as Anotações reiteram o porquê de os carnaubais serem tão importantes na paisagem local, e quais seriam suas possíveis maiores serventias:

Os carnaubais são uma nota destacada na paisagem [grifo nosso] assuense. Constituem um espetáculo maravilhoso para os olhos e para a sensibilidade poética e musical [grifos nossos]. Cobrem uma área de mais de 70 quilômetros de extensão, na direção norte-sul e produzem cêra que rende milhões para os cofres públicos e particulares (WANDERLEY, 1965, p. 30).

Nestas palavras, os carnaubais são inspiradores da sensibilidade poética e musical, numa clara intenção discursiva de os alçar a elemento indispensável da constituição identitária da paisagem, afora a rentabilidade econômica, suas utilidades cotidianas e a inspiração melopoética, ou de musicalidade própria e de seu entrelaçamento com a poética praticada neste território. Neste trecho, a referência à questão econômica dos carnaubais está em segundo plano. Tal situação já prenuncia a ênfase da simbologia em torno desta espécie vegetal em detrimento dos aspectos lucrativos, ainda que reiterados. 
Ressalta-se que, neste período, a extração da cera de carnaúba já se encontrava em declínio na região. Em outra obra deste autor, A Geografia Potiguar na Sensibilidade dos Poetas (1962), quando se remete a Assú, Rômulo Wanderley adiantava que:

O rio Piranhas, descendo dos sertões da Paraíba, penetra no território norte-riograndense, em busca do mar. Antes de sua foz, banha a cidade do Assú (28), cujas várzeas são cobertas de carnaubeiras verdes e harmoniosas [grifos nossos], porque o vento canta nas palmas dessas árvores características de uma região, formando uma paisagem a que não têm sido indiferentes os poetas (WANDERLEY, 1962, p. 60).

Mais uma vez, aparecem enunciados que reforçam a positividade discursiva que postula certa unidade para o espaço assuense, de modo que o tom harmonioso perpassa até mesmo as carnaubeiras. A paisagem por elas formada é decantada pelos poetas. Para esse escritor, os poetas possuíam sensibilidade para com o território, de modo que suas produções seriam sensações obtidas com a paisagem por meio dos sentidos. Transparece em Rômulo uma ideia de sensibilidade, enquanto, como diria Pesavento (2007), escrita e leitura na e da alma, pois em suas produções os carnaubais parecem afetar o espírito poético de seus conterrâneos, de modo que há certa internalização da paisagem que seria exteriorizada poeticamente. Para além de serem representações e construções significativas, "[...] as sensibilidades se exprimem em atos, em ritos, em palavras e imagens, em objetos da vida material, em materialidades do espaço construído" (PESAVENTO, 2007, p. 20).

As sensibilidades são expressões de um sentir, de um ver, cheirar, tocar; constituem formas pelas quais se expressam nossas sensações, responsáveis por várias maneiras de ver e dizer coisas ou propriamente um espaço por meio de materialidades como construções de objetos e palavras grafadas.

Para reforçar o decantar dos carnaubais pelos poetas, o autor, na mesma obra, apresenta um soneto do poeta Edinor Avelino, natural de Macau, mas que residiu em Assú. O soneto foi provavelmente produzido em 1923 e reproduzido por Rômulo em 1962:

\footnotetext{
Assu, formoso vale! Expressão, harmonia [grifos nossos]

Para um canto divino, poema superior

Daquele que, Anacreante [sic], em seu tempo, dizia

Cantando a formosura, a natureza e o amor.
} 
Terra boa! Visão que o habitante extasia

- Terra mãe lhe estendendo o seio acolhedor -

Onde ele achou a paz, a esperança, a alegria,

A abundância da seara e o perfume da flor!

Jardim da inspiração! Retiro doce e branco!

Cercanias que têm rebanho e zagais!

Várzea onde o rio vai, claro, se debruçando,

A distância a vence com as águas musicais,

E onde se escuta a voz dos pássaros louvando

A selva e a ostentação dos verdes carnaubais [grifos nossos]

(WANDERLEY, 1962, p. 60)

Desde já, é válido ressaltar que esse poeta foi contemporâneo de Rômulo quando colaboravam no jornal A Cidade, em edição especial de aniversário desse jornal, datada de 1928. Na folha "Artes e Letras", aparecem poemas dos dois escritores. É nesta mesma edição, inclusive, que encontramos um poema de autoria de Rômulo no qual se rastreia a subjetividade do autor para com aspectos da natureza, uma vez que seus versos intitulados Teu Jardim faziam menção a uma bela e harmoniosa natureza circunscrita a um jardim já decantado pelo autor. Assim, o fascínio pelos carnaubais fazia parte de uma subjetividade autoral ligada a aspectos da natureza (A CIDADE, 1928, p. 11).

Além do mais, não interessa aqui necessariamente a data de produção do referido soneto de Edinor Avelino, mas a apresentação dele por meio da obra de Rômulo Wanderley, oportunidade em que fica visível a intenção de ressaltar, por meio de produções poéticas, um território harmonioso, onde parece que tudo caminha mediante as inspirações da natureza e dos poemas embalados pelos verdes carnaubais.

É um espaço construído através de certo equilíbrio, no qual a cidade emerge como tranquila, antiga e tradicional, inclusive em sua paisagem, que tem como elemento fundante a carnaubeira. Daí, em um de seus discursos na Academia Norte-Rio-Grandense de Letras, publicado em 1970, sobre o título de Evocando os nossos mortos, Rômulo se reportar a mortos ilustres como poetas, escritores e homens dedicados aos estudos da história. Nesse texto, ele se remete ao assuense Nestor dos Santos Lima, dizendo 
"nascido na cidade tradicional dos carnaubais [grifos nossos] que tem servido de berço a poetas e heróis, patriotas e trovadores [...]" (WANDELEY, 1970, p. 80). Ele aí demonstra explicitamente a articulação entre carnaubais e tradição, reforçando a questão de berço da poesia e heroísmo potiguar como atributo histórico.

Rômulo costurou seus versos a ponto de enlear o leitor numa teia de produção de sentidos em que, num primeiro momento, ele é levado a acreditar que seria indissociável pensar a paisagem assuense sem a presença dos carnaubais, postos nos enunciados de maneira a denotar um espaço lendário, tidos implicitamente como constituidores de uma paisagem ao mesmo tempo presente e antiga. Vejamos mais um poema do autor aqui analisado:

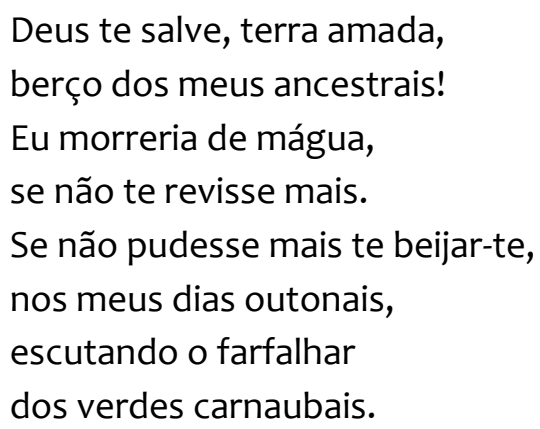

(WANDERLEY, 1965, VIII)

No final deste poema, a alusão aos "verdes carnaubais" não deve ser naturalizada enquanto dizer, pois, se o litoral possuía sua mata verde (atlântica), que posteriormente foi perdendo espaço para outro tipo de paisagem vegetal (verde), notadamente a canade-açúcar, plantada para fins comerciais desde tempos de colonização, o sertão (assuense) teria, por meio de seus carnaubais, uma área também verde em plena zona sertaneja, caracterizada pelo clima quente e seco onde predomina a caatinga.

Os carnaubais, em sua perspectiva verdejante, estão para além de uma tonalidade de cor natural das folhas da carnaubeira, uma vez que este atributo de verde parece ser uma estratégia discursiva com a função de fornecer vida a uma área caracterizada como semi-árida. É a produção de uma identidade sertaneja para além dos destinos de fronteiras que enquadram essa área como unicamente seca e quente. 

plantada "[...] no árido sertão nordestino. Ali, na terra dos verdes carnaubais [grifos nossos], onde o Piranhas ou Açu serpenteia faminto de sede" (MONTENEGRO, 1972, p. 238). Por isso, conforme Wertheim (2001, p. 224), se “[...] todos os espaços são necessariamente produções de comunidades específicas, não é de se surpreender que concepções do espaço reflitam muitas vezes as sociedades de que brotam". Os verdes carnaubais dizem da demanda da construção específica de um espaço, espaço da esperança, esteticamente belo e verdejante, arejado; portanto, outro espaço para além da negatividade climática a ele atribuída.

Prefaciando a obra O Açu no Recife (1966), de um escritor e professor assuense radicado no Recife desde os anos de 1920, Lauro de Oliveira, o escritor do Vale do CearáMirim (litoral do RN), Nilo Pereira, também radicado no Recife e professor da faculdade, referia-se à palestra de Lauro que teria dado origem à obra já citada, fazendo menção à “[...] presença dos carnaubais, que são o canavial do Açu, ondulam levemente, como o verde estendal de canas no Vale do Ceará-Mirim" (PEREIRA apud OLIVEIRA, 1966, p. 5).

Este enunciado de Nilo Pereira não deve ser compreendido somente à luz de um natural deslumbramento com os carnaubais do Assú; devem-se levar em conta as nomeações, os ditos e escritos protagonizados por assuenses, a ponto de se elevar Assú a terra dos verdes carnaubais; daí, muito do que se diz ir se efetivando na concepção dos sujeitos, principalmente se considerarmos que Nilo Pereira se encontrava radicado no estado do Pernambuco, embora fosse um amante das coisas do seu estado natal.

É ele que em 1969 publicará Imagens do Ceará-Mirim, livro no qual se propõe a apresentar mais paisagem do que história daquela cidade que, para ele, era imortal. Chamamos a atenção para este ponto, pois, além de sua cidade natal ser um espaço rodeado por canaviais, transparece que alguns escritores desse momento de escrita buscaram construir suas espacialidades, fabricando espaços através de cenários constituídos de matas (verdes), estas articuladas com sensibilidades poéticas, denotando 
um esforço por marcar o espaço pela relação da paisagem verdejante com a poética. É assim que Nilo recorda o Vale do Ceará-Mirim de seu tempo de menino:

Gosto de rever êsse velho Ceará-Mirim, de contemplar o vale ao longe, onde tantos trabalharam; onde tantos foram heróis e santos; onde um sôpro leve da poesia agita o que o Dr. Augusto Meira, patrono da vossa Escola, chamou, num antigo soneto de 1916, "a maré montante dos canaviais". O verde macio e ondulante encanta meus olhos (PEREIRA, 1969, p. 129).

Movimento semelhante foi operado por outros escritores no sentido de fazer valer os verdes carnaubais da cidade do Assú e da Região Vale, com o intuito de fazer com que a identidade da cidade e região fosse atrelada às folhas verdes das carnaubeiras constantes no território local.

No que tange a cidade, manifesta-se, assim, nessa empreitada, um sentido de tradição, a tentativa de inventar discursivamente a tradição dos verdes carnaubais assuenses. Gesta-se um movimento de alçamento da paisagem tradicional do Assú por meio dos carnaubais. Neste sentido, Lauro de Oliveira, quando trata de sua infância em Assú, menciona que “o que me cumpre ressaltar, aqui, é minha lembrança presente de meus tempos de menino, no meu Açu, de lindos carnaubais que desempenham, na estação invernosa, o papel de autênticos para-raios" (OLIVEIRA, 1966, p. 12).

Para ele, os carnaubais teriam uma força sobrenatural a ponto de conterem os raios advindos do plano celeste; ainda mais, seriam "verdadeiras" salvaguardas em tempos invernosos, uma espécie de blindagem vegetal do Assú. Deve-se registrar que a obra de Lauro teve origem numa palestra que proferiu na Faculdade do Recife na oportunidade do lançamento de um dos livros de Rômulo Wanderley, a saber: Panorama da Poesia Norte-Rio-Grandense.

Esta sua recordação torna-se compreensível quando se leva em consideração a assertiva de Bachelard - mesmo considerando que este autor escreveu a partir de uma área de clima temperado -, ao dizer que "de todas as estações do ano, o inverno é a mais velha. Põe tempo nas lembranças" (BACHELARD, 1978, p. 224). Isto é, as estações invernosas emergem em grande parte como arsenais da memória, pois esta geralmente provoca maiores preocupações, cuidados, especulações, crenças e ritos, principalmente 

inquietam com seus espaços de proteção. Assim, a conotação pela qual os carnaubais são narrados projeta-os como um tipo de telhado protetor do Assú. Em se tratando de telhado, não podemos deixar de atentar para uma questão importante neste ponto da discussão, notadamente para o alerta que “[...] os geógrafos não deixam de lembrar que, em cada país, a inclinação do telhado é um dos sinais mais seguros do clima" (BACHELARD, 1978, p. 224). Observa-se, assim, que os verdes carnaubais são inclinados discursivamente para não só "proteger" o espaço assuense das estações climáticas quentes e secas, mas também dos períodos invernosos.

Podemos vislumbrar tal perspectiva por meio de uma das imagens contidas em Canção da Terra dos Carnaubais, em que percebemos a tentativa de alçar as carnaubeiras acima do contexto citadino assuense como se elas fossem realmente o teto da cidade, protegendo, inclusive, os antigos e históricos sobrados. Caso a intenção do autor e da equipe editorial da obra fosse representar o chamado Sobrado da Baronesa (Centro histórico da cidade - Quadro da Rua) e independente de por trás desta arquitetura existir ou não a referida espécie vegetal, devemos chamar a atenção para o caráter construtivo da linguagem visual, pois a carnaubeira poderia não aparecer, até porque, especificamente no poema abaixo da imagem, ela não é mencionada.

Todavia, sua inserção na imagem denota, por outro lado, a articulação de enunciados que, juntos, põem em funcionamento certa lógica de pertencimento e reconhecimento do espaço assuense, pois a imagem atua neste caso, para mostrar o quanto a carnaubeira faz parte do cenário local, fazendo dele um quadro eminentemente histórico e arquitetônico, pois os sobrados são tidos pelos cidadãos, particularmente pelos que emitem dizeres sobre a cidade - durante a segunda metade do século XX -, como espaços históricos, nobres e significativos da cultura local. 
Nestes termos, os sobrados são escrituras familiares, pessoais, registros de um nome, de um valor sentimental, mas também econômico. Daí admitir-se, em relação a estas construções, votos de valorização e culto. Analise-se a imagem seguinte:

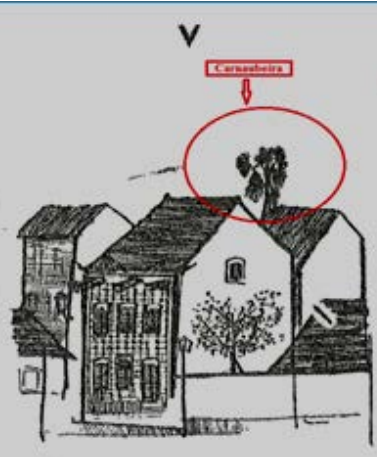

INHA terra tem história,

W poesia e tradição! (13)

E em tempos idos, já foi

a Atenas do meu sertão. (14)

Antigamente, a escola

lá era risonha e franca, (15)

e o negro, banqueteado,

nos salões do amplo sobrado

do Barão de Serra Branca. (16)

Figura 1: Imagem contida no livro Canção da Terra dos Carnaubais (1965, V).

Sinalização: Roberg Januário dos Santos.

Não se estranha a utilização simbólica dos carnaubais na produção do celebrado espaço, uma vez que a memória de uma paisagem garante o reconhecimento do lugar em meio a outras referências territoriais, o que permite um ancoradouro vegetal para uma definição espacial.

Compreendendo que um território também é construído por um feixe memorial, muitas vezes fruto de uma tentativa de recordação grupal, Halbwachs assinala que não há memória coletiva que não ocorra em um contexto espacial, bem como evidencia, em relação a grupos urbanos, que "os costumes locais resistem às forças que tendem a transformá-los e essa resistência permite entender melhor a que ponto nesse tipo de grupo a memória coletiva se apoia em imagens espaciais" (HALBWACHS, 2006, p. 162).

Na imagem apresentada na figura 1, presente no livro de Rômulo Wanderley, a carnaubeira aparece numa dimensão altaneira, aspecto também visualizado em outra imagem de seu livro, representação em que as carnaubeiras apresentam perfil 
organizado e ordenado. A imagem abaixo fornece um aspecto de progressão dado às carnaubeiras que, na forma como foram dispostas, denotam, pela arrumação do conjunto, uma infinidade, certo apresentar-se de um longe que se aproxima, ótica esta que promove uma percepção de extensão:

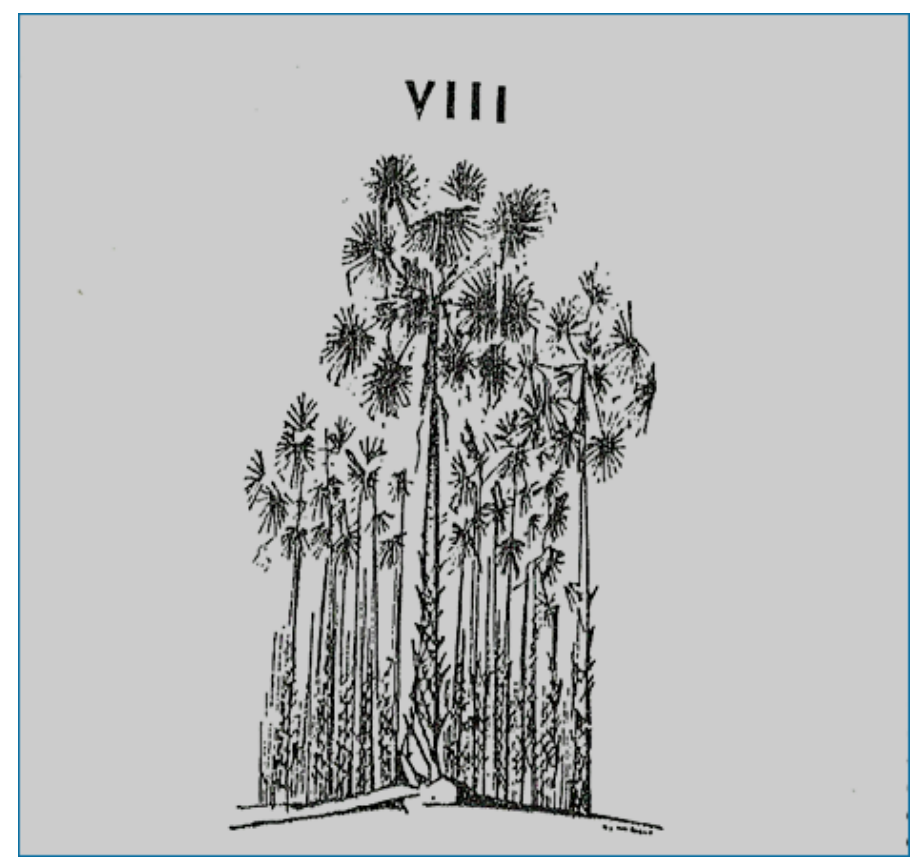

Figura 2: Imagem contida no livro Canção da Terra dos Carnaubais (1965, VIII).

A ilustração denota um tipo de produção imagética de paisagem, uma produção específica, pois o trato no posicionamento das carnaubeiras traduz uma ação interessada. Daí Schama (1996) mencionar uma de suas percepções de paisagem, oportunidade em que considera que "nem todas as culturas abraçam natureza e paisagem com igual ardor, e as que abraçam conhecem fases de maior ou menor entusiasmo" (1996, p. 25).

Assim, poderíamos aventar que cada sociedade emite, em relação à natureza que a cerca, camadas de significação e que, por isso, a linguagem (escrita) se torna uma operadora de paisagens, pois conecta interesses, estabelece links que promovem acessos à natureza, virtualiza espaços de contato, permitindo interatividade entre sujeitos e elementos naturais.

Daí concentrar-se esta análise discursiva nos enunciados que promovem esta relação no âmbito do presente estudo, pois o discurso é um tipo de linguagem mais 
abrangente, que inclui aspectos pragmáticos, promotores, já que linguagem é ação e, como diria Araújo (2004, p. 209), “o mundo não contém unidades discretas, a serem simplesmente representadas; ele é constituído pela forma como designamos as coisas [...]”. A linguagem funciona como condução e alvo de relações complexas de saber e poder, não se reduzindo ao puro e simples conjunto de regras linguísticas.

Desse modo, em outro escrito constante na documentação do IHGRN, localiza-se mais uma vez o enunciado dos carnaubais atrelado a outro enunciado de cunho estritamente histórico, ocasião em que na Revista, de 1952, sob a redação de Nestor Lima e outros membros do instituto, era apresentado artigo acerca de $O$ Fogo de 40, contenda política ocorrida em 1840 em Assú. Naquele ano, após a anulação das eleições municipais, agentes políticos liberais e conservadores se enfrentaram armados em praça pública, culminando com pessoas feridas e mortas. O referido artigo informa que "O FOGO DE 40 é o episódio mais recordado no Município do Assú. Quem visita a Cidade ouvirá a evocação, indicados os lugares, reconstituídas as cenas, figuras e pormenores" (REVISTA DO IHGRN, 1952, p. 194).

Assim, compreendemos quão grande era o interesse dos redatores em mostrar o quanto o referido acontecimento estava fixado na memória dos habitantes, a ponto de estes se aventurarem numa tentativa de detalhar o evento transcorrido em 1840. Além do mais, o artigo se encerra com o seguinte discurso acerca de O Fogo de 40, por sua vez fazendo menção à antiga Vila Nova da Princesa, ${ }^{5}$ relatando:

Quem morreu, morreu. Os olhos secaram. Os políticos viveram. Outras eleições vieram, custando vidas. Os anos foram passando, cobrindo, com a terra dos tumulos, as testemunhas da tragédia.

Ficou, na memória dos assuenses, o episódio terrível. Nas Tardes macias, quando o vento ardente faz acenar as palmas dos carnaubáis sussurrantes, amam os velhos do Assú evocar o dia inesquecido [grifos nossos], e as mãos se erguem, vagarosas, apontando, resuscitando, vivendo os momentos rubros do "Fôgo de 40"..." (REVISTADO DO IHGRN, 1952, p. 202).

Considera-se importante atentar para a cena montada pelos narradores no sentido de fazer crer no que escreveram, pois os momentos de evocação de o Fogo de 40 são

\footnotetext{
${ }^{5}$ Em 1788 Assú foi elevado à condição de Vila.
} 

ponto de estes influírem no aflorar das recordações.

Os carnaubais, neste caso, servem como elementos provocadores de reminiscências, mesmo que seja a reminiscência dolorosa de uma tragédia, já que no conflito armado houve mortos. Mas é preciso compreender que a memória desse tipo de situação concorre para a produção de identidade, pois, geralmente, um evento que resulte em lacrimatório serve como suporte para projetos de identificação que se pretendem coletivos, uma vez que, de acordo com Candau (2011), se tenta instaurar certo sofrimento coletivo, fomentando, assim, modos de apego.

Em se tratando de IHGRN, este instituto patrocinou o livro ASSÚ - Atenas NorteRiograndense (1966), de autoria de João Carlos Vasconcelos. Este, ao oferecer a feitura de sua obra a cidadãos assuenses, se expressava dizendo: "aos prezados amigos diletos filhos da terra dos carnaubais" (VASCONCELOS, 1966, p. 18).

Já em outro momento da referida produção, o autor escrevia que "grande é a lista dos filhos do Assú que, pela sua inteligência, muito devem as letras e a cultura da terra dos carnaubais". Seria, assim, mais um escrito advindo do IHGRN, que menciona Assú como terra dos carnaubais. E mais, num livro que se presta a falar do Assú enquanto "Atenas Norte Rio-Grandense", 6 a inclusão dos carnaubais denota a articulação de elementos simbólicos, como carnaubeira e poesia, reforçando a "tese" da terra da poesia inspirada pela presença dos carnaubais.

Chama-se a atenção aqui para o seguinte fator: embora a investida discursiva em torno dos carnaubais comece a ecoar antes de 1950, é na segunda metade do século XX que se observa uma maior enunciação dos "verdes carnaubais". Nela se percebe uma franca pretensão de se produzir uma paisagem simbólica para Assú. Também pode,

\footnotetext{
${ }^{6}$ Em nossa pesquisa de mestrado também problematizamos a emergência desse epíteto. Constatamos que o referido epíteto emerge historicamente na segunda metade do século XX. Fruto de vários enunciados, a "Atenas Norte-Rio-Grandense" foi produzida na e pela linguagem para soerguer uma terra de história, poesia e tradição.
} 
implicitamente, traduzir outra questão, a saber: com a crise das chamadas economias tradicionais (algodão, óleos, agave e cera de carnaúba) do Rio Grande do Norte registrada a partir dos anos de 1960, há uma forte possibilidade de as velhas lideranças assuenses, que mantinham status e poder mediante a extração da cera de carnaúba, terem começado a visualizar um panorama de descrédito para tal atividade e, por conseguinte, de descrédito dos poderes com ela conquistados.

A forte ênfase sobre os carnaubais, em termos de adjetivação, pode ser, neste sentido, uma provável investida discursiva para não se perder o poder por eles representado, já que antes provinha justamente da rentabilidade financeira; já no pós 1960-1970, a ênfase transferia-se para o âmbito do simbólico. Assim, o poder em torno dessa espécie vegetal se deslocaria da matriz econômica para a matriz cultural e, por conseguinte, paisagística.

Além do mais, a decaída da importância econômica dos carnaubais já era aviltada no Vale do Açu antes da década de 1960, uma vez que as constantes investidas no sentido de tornar as terras da região agricultáveis implicava substituir esse tipo de economia, com planos de irrigação montados para a área do Baixo Assú, ${ }^{7}$ logisticamente encaminhados pela presença da Igreja Católica através da Diocese da cidade de Mossoró/RN e o Governo J.K.

Desse modo, já em 1956, o assuense Osvaldo Amorim, homem que, embora de família de projeção local, fazia naquele momento discursos considerados progressistas e pregava para a região a modernização agrícola, em um de seus discursos veiculado no Jornal O Mossoroense, do qual ele era correspondente, escrevia:

É imperiosa a precisão de modificarmos o mito de Grandes produtos de cêra de Carnauba. Carnaubais existem, mas estão nas mãos de poucos, sendo que a maioria é carnaubal de 30 arrobas. Precisamos modificar o sistema da vida sob fundamento de renda do carnaubal e passarmos a produzir tudo o que a terra pode nos dar (AMORIM, O. 1956, p. 4).

O enunciado demonstra que, embora a concentração de riqueza proveniente dos carnaubais estivesse nas mãos de poucos, apresentava um quadro que estava reduzindo

\footnotetext{
7 Área destinada à fruticultura irrigada no Vale do Açu, situada entre os municípios do Assú e Alto do Rodrigues.
} 
sua produção, o que leva a pensar que, se em grande parte existia um baixo rendimento de parte dessa espécie vegetal, a situação atingia os grandes proprietários envolvidos na comercialização da cera de carnaúba, já que, no ciclo do carnaubal, os lucros não provinham somente das propriedades dos senhores ricos e comerciantes, mas da compra da produção dos carnaubais de pequenos proprietários espalhados pela região.

Reforçando essa concepção e esclarecendo acerca de prenúncios do enfraquecimento da economia dos carnaubais, o mesmo jornalista, autor da matéria da qual extraímos o excerto acima, escrevia, no mês seguinte (agosto), reforçando o que dissera no mês anterior, ensejo em que defendia a vinda para o Vale do Açu de imigrantes japoneses que possuíssem experiência agrícola para desenvolver a região. Assim, ele apontava, com relação ao Vale, particularmente à margem esquerda do Rio Assú, que:

Pela concentração humana, pela riqueza incomensurável de suas terras, merece receber o amparo e a ajuda dos poderes públicos. Mais de mil propriedades, pequenas propriedades, ali estão encravadas, nada produzindo alem da minguada produção de Cera de Carnauba. Fora disto, o homem da Varzea, não sabe como aproveitar o maximo do rendimento, de suas terras, não só porque está preso a uma agricultura medieval, quiça pela falta absoluta de assistencia tecnica e da propria educação rural (AMORIM, O. 1956, s/p).

Somando com o que está posto nos enunciados acima, devemos advertir que a produção e comercialização de cera de carnaúba alcançou seu auge no Vale do Açu entre 1940 e 1945, ocasião em que as necessidades geradas pela Segunda Guerra Mundial, principalmente da indústria bélica, faziam com que a cera fosse produto de pauta das exportações do estado. Portanto, após este período, nota-se um paulatino decréscimo da importância econômica do produto.

Já o escritor assuense Francisco Amorim, por sua vez defensor do cooperativismo na Região do Vale e na cidade do Assú, em artigo no mesmo jornal do qual Osvaldo era correspondente, escrevia, em dezembro de 1958, advogando a criação de uma cooperativa específica para os produtores de cera de carnaúba do Assú, em função das várias dificuldades vividas pela economia da cera dela extraída. Observa-se nesse enunciado, inclusive, o apontamento do declínio dessa economia. Assim ele se expressava: 
Com a elevação do braço, a majoração dos impostos, e consequentemente, o alto custo de vida dos preços, o apogeu do ciclo da cera de carnaúba declinou assustadoramente [grifos nossos]. Podemos mesmo dizer que foi o único produto que, relativamente, não acompanhou a evolução dos preços.

Há mais de dez anos passados, a cera de carnauba obteve melhores preços que os atuais o que não se verificou com a totalidade dos outros produtos.

Diante, pois, de tamanha conjuntura o que devem fazer os senhores donos de carnaubais?

Não existe outra alternativa: a organização de uma COOPERATIVA DA CERA DE CARNAUBA (AMORIM, F. 1958, p. 3).

O que chama a atenção em relação a Francisco Amorim é que, por meio dele, se pode observar esse movimento que expressa um tipo de transferência de poder econômico para um poder simbólico dos carnaubais, pois, se em 1958 ele escrevia sobre o declínio econômico da referida espécie, em 1971 ele se remetia à história do Assú, em artigo divulgado pelo mesmo jornal, de modo a enfatizar não mais a economia dos carnaubais, mas sua presença enquanto constituintes da paisagem, oportunidade em que se referia ao $126^{\circ}$ aniversário de emancipação política da cidade e referenciava que se vivia um momento de "[...] ilustração, projeção e destaque ao torrão nativo onde à tarde a brisa nordestina acaricia e balança as verdes palmas das carnaubeiras" (AMORIM, F. $1971, \mathrm{~s} / \mathrm{p})$.

Assim, fica a pertinência da questão posta neste trabalho, pois os escritos acerca dos carnaubais emergem da formação discursiva aqui investigada, através de sujeitos em sua maioria nativos, que conviveram ou possuíam vínculos genealógicos com grupos que se beneficiavam da economia da cera de carnaúba.

Outra evidência que denota uma investida simbólica por meio dos carnaubais é a medida tomada pelo poder público municipal do Assú ao adotar uma bandeira na qual se faz alusão direta a esse espécime vegetal. Desse modo, em 1969, mediante a Lei 06/69, que estabeleceu o distintivo da bandeira do município e oficializava a letra e música do hino do Assú, observamos que os carnaubais aparecem nos dois elementos. Assim, quanto ao hino, com letra de autoria de Sinhazinha Wanderley, em um dos trechos se faz menção direta aos carnaubais, ensejo em que novamente se realça a utilidade desta espécie durante as estações climáticas regionais: 
Qual um canto harmonioso

Das aves, pelo ramado

A minh'alma te festeja

Meu Assú, idolatrado.

Estribilho

Torrão bendito hei de amar-te

Dentro do meu coração

Salve, Assú estremecido,

Salve, salve ó meu sertão.

Palmeiral da minha terra

As várzeas cobrindo estás

Tu que és útil pelo inverno

E pela seca ainda mais [grifos nossos].

Valoroso, florescente,

Em face dos mais sertões

Hão de erguer-te o nosso esforço

Nossos bravos corações.

(SÍMBOLOS E HINOS, 2012).

Já o desenho e a descrição da bandeira foi obra do assuense João Marcolino de Vasconcelos, o conhecido dr. Lou, um entusiasta da vida literária e poética local, que conviveu com boa parte da geração de escritores do Assú, inspirando-se neles para se dedicar também a uma poética do espaço. Seus discursos, na maioria, convergiam para o campo cultural de sua cidade, tornando-se, assim, um dos membros da rede discursiva que investe sobre o Assú suas forças no sentido de torná-la uma terra de história, poesia e tradição. Por isso, a bandeira diz acerca dessa perspectiva identitária: 


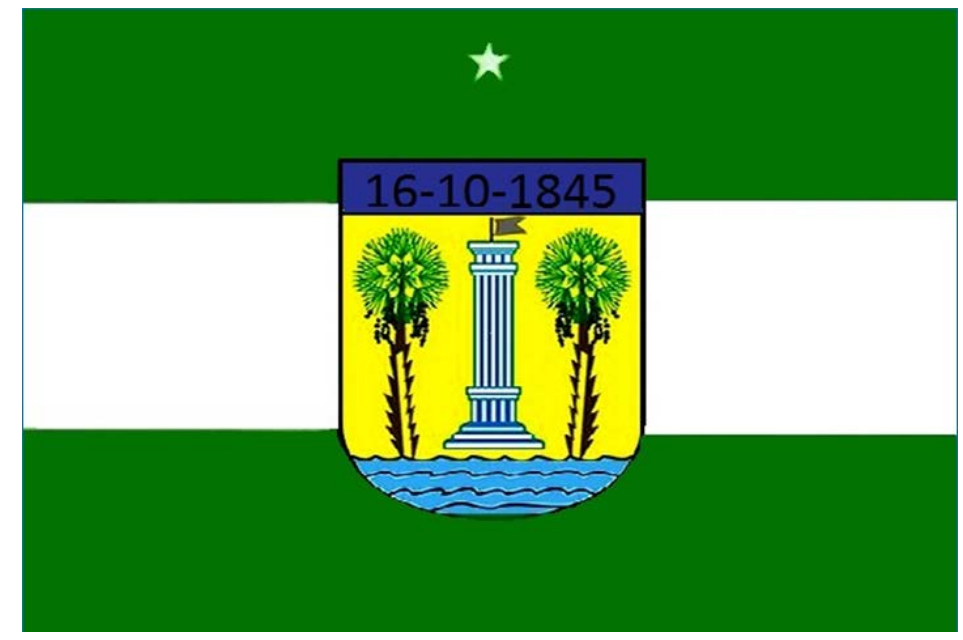

Figura 3: Bandeira do municipio do Assú/RN. Fonte: Símbolos e hinos. Prefeitura municipal do Assú (http://assu.rn.gov.br/). Acesso em: $1^{\circ}$ de abril de 2012.

Para melhor analisar o distintivo da bandeira, apresenta-se o Art. $2^{\circ}$ da Lei 06/69, pois ele mostrará quão grande significação os carnaubais assumem como símbolo do espaço assuense:

Art. $2^{\circ}$ - A bandeira a que se refere o artigo anterior será constituída: de um retângulo com as cores verde e branca, caracterizando a exuberância da terra e a paz nela reinante, dispostas de conformidade com o modelo anexo, tendo ao centro um escudo amarelo, em forma de " $U$ ", que, na sua cor, simboliza a riqueza e, na sua forma, a união, e neste a coluna histórica da passagem do século, ladeada por duas carnaubeiras, palmeiras típicas da região, formando no seu conjunto como que uma lira, encimada por uma faixa de cor azul, representativa do céu, com a data histórica de 16.10.1845, tendo acima desta uma estrela, de cor branca, significativa do nascimento do Açu-cidade e, sob a base da coluna as cores características da água, representando os rios e o principal lago do município (COLETANEA LITERÁRIA ASSUENSE, 1977, s/p).

Observa-se, nesse distintivo da bandeira, a imagética da formação discursiva sobre o Assú, pois o verde dos carnaubais ocupa boa parte do retângulo da bandeira; observamos, mais, a presença de duas carnaubeiras ladeando a coluna histórica, o que evidencia sua projeção dos carnaubais enquanto elementos fundantes da paisagem assuense.

Além disso, a história é bastante ressaltada na confecção desse distintivo, haja vista termos aí a coluna histórica da passagem do século XIX para o século XX, a estrela e a data de 16 de outubro de 1845, simbolizando a emancipação política da cidade. Não 
esqueçamos haver aí duas situações que denunciam certa ótica religiosa na feitura do distintivo, pois a coluna histórica foi considerada uma homenagem de fé do povo assuense, razão, naquele momento, da estatua de Jesus Cristo em seu cume.

A se observar, também, que a data histórica do município se encontra inserida num espaço de cor azul que simboliza o céu, ou seja, o céu converge para a perspectiva do paraíso, por isso, daí o hino adotado se referir, pela mesma lei, ao Assú como "canto harmonioso". Por fim, aparecem na parte inferior do distintivo as águas que fazem menção ao Rio Assú e à Lagoa do Piató (localizada em território assuense).

Outra perspectiva contida na bandeira é de ordem patriótica, na medida em que segue em parte os tons da bandeira brasileira e do Rio Grande do Norte, que apresenta o verde em destaque (menção à natureza), o amarelo (riqueza), o branco (paz) e o azul, justamente dentro do escudo, sem esquecer da estrela postada na parte superior da bandeira assuense, a exemplo daquela que existe na bandeira estadual.

A carnaubeira assumiria, neste sentido, a função de símbolo de toda a paisagem do Assú, já que a bandeira oficial do município o apresentava como espécie de destaque no cenário confeccionado. Aí está mais uma ação que buscou projetar o poder simbólico dos carnaubais. Dessa feita, o poder público municipal investia para reafirmar a paisagem assuense, constituída pelos “verdes carnaubais", ação que expressa certo jogo de produção identitária em relação à região do Vale quanto ao estado, uma vez que nas circunvizinhanças do Assú existia outro município, que antes pertencia ao seu domínio: falamos do município de Carnaubais que, a partir de 1963 se emancipou. Em relação ao estado, possivelmente seria interessante dirimir a imagem de território quente, seco, sem vida, daí a terra dos verdes carnaubais se configurar como resposta a tal visão, projetando um novo epíteto para a cidade, que se somaria aos demais já existentes.

\section{Conclusão}

Observam-se nos enunciados analisados neste trabalho estratégias de produção da identidade e, por conseguinte, do espaço assuense, já que produzir ou praticar o espaço passa pelo posicionamento tomado em relação a ele, ocupando um lugar de onde 
se busca se alcançar algo. É a provocação de um efeito; é o se posicionar em relação a outros posicionamentos externos; é a hora e a vez das demarcações, delimitações e impressões. Como diria Albuquerque Junior, os espaços se constituem em "zonas de encrenca", notadamente porque o posicionamento implica o exercício do poder, daí a análise das histórias dos espaços requerer a crítica sobre as relações de poder que se configuram nesses territórios, pois em todo o tecido social é perceptível a distribuição de lugares, a demarcação de domínios e ambientes (ALBUQUERQUE JÚNIOR, 2013).

Assim, o alçamento dos carnaubais como paisagem assuense é fruto de uma demarcação espacial; é resultado de práticas estratégicas situadas no âmbito das relações de força que visam a instituir uma identidade cultural para a cidade utilizando uma espécie vegetal. É a busca da posse; é a tomada de posição de fazer dessa espécie patrimônio vegetal.

Todavia, devem-se levar em consideração os apontamentos de Silva (2009) quanto ao caráter da linguagem e da identidade, pois, segundo ele, assim como ocorre na linguagem, a tentativa de fixar uma identidade não é frutífera, pois ambas escapam à fixação. Pode-se observar, no objeto de saber e poder analisado, a complexa teia de enredos que possibilitaram a formação discursiva acerca do Assú e, por conseguinte, sobre a terra dos verdes carnaubais. Constata-se que esta formação não se restringe a um ponto de partida; ela é um feixe de relações e dizeres que imprimem uma regularidade imagético-discursiva de modo que a cidade seja reconhecida pelos atributos já citados neste texto.

A recorrência aos verdes carnaubais nos enunciados problematizados oportunidade em que a cidade emerge enquanto terra dos verdes carnaubais ou somente dos carnaubais -, faz do conjunto produto simbólico e significativo para reforço da positividade do discurso que postula um arquivo de imagens e discursos acerca do Assú, pois vários enunciados se prestam a esta articulação no âmbito da formação discursiva ou na regularidade dos discursos, observando-se certa ênfase em promover a relação dos poetas e poesias, bem como de acontecimentos históricos, com a carnaubeira. 
No âmbito desta análise, acredita-se que a (de)marcação do espaço assuense enquanto terra dos verdes carnaubais foi uma construção interessada, uma produção com fins identitários. Essa terra ganhou notoriedade na segunda metade do século $X X$, em especial entre as décadas de 1950 e 1970, período em que foram investidas forças discursivas para consolidar uma imagética da paisagem da cidade. A produção do espaço assuense, neste caso, passa pela fabricação de um epíteto, ou por um dizer que realça a sua significação. Este movimento da linguagem escrita e, por conseguinte, discursiva, ocorre concomitantemente à construção de uma paisagem ímpar para o Assú, a saber: a paisagem dos verdes carnaubais. Esta paisagem emerge de uma cultura escrita, cruzada pelas relações de saber e poder, construtoras do espaço assuense, pois a construção desse espaço se dá através de elementos tradicionalmente reivindicados como definidores de identidades espaciais, a exemplo de distinta produção literária, heroísmo militar e natureza exuberante.

Dessa forma, ao esmiuçar as costuras discursivas dos enunciados acerca dos carnaubais assuenses, espera-se ter conseguido provocar questionamentos acerca da historiografia e literatura tradicionais, que investem na positividade do discurso da tradição local, principalmente no que diz respeito à produção desse espaço enquanto terra dos carnaubais. Nesses termos, o princípio de uma história grande e de uma terra dos poetas é unido e manipulado para se relacionar com a paisagem vegetal. Este trabalho, iniciado com uma epígrafe de Schama, se encerra com citação do mesmo autor, repetindo sua a ideia de que "paisagem é cultura antes de ser natureza” (1996, p. 70).

\section{Referências}

A cidade. Assú, Rio Grande do Norte, n. XXVIII, a. 709. 8 dez.1928. Edição de hoje, 12 páginas ilustradas.

ALBUQUERQUE JÚNIOR, Durval Muniz de. Zonas de encrenca: algumas reflexões sobre poder e espaços. Disponível em: <http://www.cchla.ufrn.br/ppgh/docentes/durval/ artigos/segunda_remessa/zonas_de_encrenca.pdf >. Acesso em: $1^{\circ}$ jan. 2013.

AMORIM, Francisco. Uma cooperativa. In: O Mossoroense. Mossoró (RN), n. 120, a., XIII, 
12 dez. 1958. p. 3 .

. A presença de Açu da taba-indígena a' atualidade. In: O Mossoroense. Mossoró (RN), 16 out. $1971 . \mathrm{s} / \mathrm{p}$.

AMORIM, Osvaldo. Ainda imigrantes para o Vale. O Mossoroense, Mossoró (RN), 24 de agosto de $1956 . \mathrm{N}^{\circ} .575$, ano $\mathrm{X}$.

.Notas Sobre o Assú. O Mossoroense, Mossoró (RN), 8 de julho de 1956, n. 541, ano X, Notícias do Interior, p.4.

ARAÚJO, Inês Lacerda. Do signo ao discurso: Introdução à filosofia da linguagem. São Paulo: Parábola Editorial, 2004

BACHELARD, Gaston. A poética do espaço. In: A filosofia do não; O novo espírito cientifico; A poética do espaço. São Paulo: Abril Cultural, 1978, p. 183-354.

CANDAU, Joel. Memória e identidade. Tradução: Maria Letícia Ferreira. São Paulo: Contexto, 2011.

COLETANEA LITERÁRIA ASSUENSE. Publicação comemorativa à passagem do $132^{\circ}$ aniversário da elevação do Assú à categoria de cidade. Coleção Assuense, nº. 001, 1977, s/p.

FOUCAULT, Michel. A Arqueologia do saber. Trad. Luiz Felipe Baeta Neves. 8. ed. Rio de Janeiro: Forense Universitária, 2012.

HALBWACHS, Maurice. A memória coletiva e o espaço. In: A memória coletiva. Trad. Beatriz Sidou. São Paulo: Centauro, 2006, p. 157-190.

MEDEIRO, Maria Lucélia S. de. Lira de Poti (obra). Disponível em: <http//www.memorialantoniosoares.xpg.com.br/obra.htm>. Acesso em: 12 jan. 2013.

MONTENEGRO, Maria Eugênia Maceira. De Nísia Floresta a Rômulo Wanderley. In: Revista da Academia Norte-Rio-Grandense de Letras. Natal, n. 10. a. XXI, 1972. p. 231-246.

OLIVEIRA, Lauro de. O Açu no Recife. Recife: Imprensa Oficial, 1966.

PEREIRA, Nilo. Imagens do Ceará-Mirim. Natal: Imprensa Universitária, 1969. 
PESAVENTO, Sandra Jatahy. Sensibilidades: escrita e leitura da alma. In: PESAVENTO, Sandra Jatahy; LANGUE, Frédérique. Sensibilidades na história: memórias singulares e identidades sociais. Porto Alegre: Editora da UFRGS, 2007, p. 9 -21.

REVISTA DO INSTITUTO HISTÓRICO E GEOGRÁFICO DO RIO GRANDE DO NORTE - IHGRN. O Fogo de 40: notas da história do Assú. Edição especial consagrada ao $1^{\circ}$ cincontenário de fundação do instituto, a 29 de março de 1952. Natal, p. 194-202, v. XLVIII - XLIX. Tipografia Galhardo, 1952. p. 194.

SCHAMA, Simon. Paisagem e memória. São Paulo: Companhia das Letras, 1996. p. 29.

SILVA, Tomaz Tadeu da. A produção social da identidade e da diferença. In: SILVA, Tomaz Tadeu da (org.). Identidade e diferença: a perspectiva dos estudos culturais. 9. ed. Petropólis, RJ: Vozes, 2009.

SILVEIRA, Celso da (Org.). Paisagens da Minha terra. Assú: Editora Nordeste Gráfica, 1990.

SÍMBOLOS E HINOS. Prefeitura Municipal do Assú. Disponível em <http://assu.rn.gov.br/>. Acesso em: $1^{\circ}$ abr. 2012.

SOARES, Antônio. Lira de Poti. Imprensa Universitária, 1971.

VASCONCELOS, João Carlos de. ASSÚ - "Atenas Norte - Riograndense”. Natal: Instituto Histórico e Geográfico do Rio Grande do Norte, 1966.

WANDERLEY, Rômulo Chaves. A Geografia Potiguar na Sensibilidade dos Poetas. Coleção Henrique Castriano. Natal, 1962.

WANDERLEY, Rômulo Chaves. Canção da Terra dos Carnaubais. Natal: Departamento de Imprensa, 1965.

WANDERLEY, Rômulo Chaves. Evocando os nossos mortos. Revista da Academia NorteRio-Grandense de Letras. Natal, n. 8. p. 76- 83. Ano XIX, 1970.

WERTHEIM, Margaret. Uma história do espaço de Dante à internet. Rio de Janeiro: Jorge Zahar Ed, 2001. 
Recebido em: 03/02/2013 Aprovado em: 23/04/2013

Universidade do Estado de Santa Catarina - UDESC

Programa de Pós-Graduação em História - PPGH

Revista Tempo e Argumento

Volume 05 - Número 09 - Ano 2013

tempoeargumento@gmail.com 